\title{
Burgess Shale-type microfossils from the middle Cambrian Kaili Formation, Guizhou Province, China
}

Thomas H.P. Harvey, Javier Ortega-Hernández, Jih-Pai Lin, Zhao Yuanlong, and Nicholas J. Butterfield Acta Palaeontologica Polonica 57 (2), 2012: 423-436 doi: http://dx.doi.org/10.4202/app.2011.0028

Diverse carbonaceous microfossils, including exceptionally preserved remains of non-biomineralizing metazoans, are reported from a basal middle Cambrian interval of the Kaili Formation (Guizhou Province, China). The application of a gentle acid maceration technique complements previous palynological studies by revealing a larger size-class of acritarchs, a richer assemblage of filamentous microfossils, and a variety of previously unrecovered forms. Metazoan fossils include Wiwaxia sclerites and elements derived from biomineralizing taxa, including chancelloriids, brachiopods and hyolithids, in common with previously studied assemblages from the early and middle Cambrian of Canada. In addition, the Kaili Formation has yielded pterobranch remains and an assemblage of cuticle fragments representing "soft-bodied" worms, including a priapulid-like scalidophoran. Our results demonstrate the wide distribution and palaeobiological importance of microscopic "Burgess Shale-type" fossils, and provide insights into the limitations and potential of this largely untapped preservational mode.

Key words: Kaili biota, Priapulida, acritarchs, palynology, taphonomy, Cambrian, Guizhou Province, China.

Thomas H. P. Harvey [thph2@cam.ac.uk], Javier Ortega-Hernández [jo314@cam.ac.uk ], and Nicholas J. Butterfield [njb1005@cam.ac.uk], Department of Earth Sciences, University of Cambridge, Downing Street, Cambridge, CB2 3EQ, UK; Jih-Pai Lin [jplin@ @otmail.com ], State Key Laboratory of Palaeobiology and Stratigraphy, Nanjing Institute of Geology and Palaeontology, Chinese Academy of Sciences, Nanjing 210008, China; Zhao Yuanlong [zhaoyuanlong@ 126.com], College of Resources and Environmental Engineering, Guizhou University, Guiyang, 550003, China.

This is an open-access article distributed under the terms of the Creative Commons Attribution License (for details please see creativecommons.org), which permits unrestricted use, 
distribution, and reproduction in any medium, provided the original author and source are credited.

Fof Full text $(895.3 \mathrm{kB})$ 